\title{
Renal and intrarenal blood flow in non-cirrhotic portal hypertension
}

\author{
M. C. KEW, CAROL LIMBRICK, R. R. VARMA, AND SHEILA SHERLOCK \\ From the Departments of Medicine and Medical Physics, Royal Free Hospital, London
}

SUMMARY The effect of portal hypertension or the consequent portal circulatory changes on renal haemodynamics was studied using the ${ }^{133}$ xenon washout technique. Renal blood flow was reduced in nine of 11 patients with non-cirrhotic portal hypertension and this was accompanied by a redistribution of intrarenal blood flow, the distribution to and flow rate through the outer cortex being reduced while juxtamedullary and medullary flow was maintained. With slight or moderate decreases in cortical flow glomerular filtration was normal but poor cortical perfusion was associated with low creatinine clearances. These findings raise the possibility that portal hypertension or portal circulatory changes may play a role in the pathogenesis of the renal haemodynamic changes and functional renal failure which frequently complicate advanced hepatic cirrhosis.

It is generally agreed that the renal failure which develops in cirrhotic patients in the absence of primary renal disease or factors known to cause acute tubular necrosis has a functional basis (Papper, Belsky, and Bleifer, 1959; Baldus, Feichter, and Summerskill, 1964a; Baldus, Feichter, Summerskill, Hunt, and Wakim, 1964b; Koppel, Coburn, Mims, Goldstein, Boyle, and Rubini, 1969). The nature of the renal dysfunction has not definitely been established but evidence is accumulating that the primary disturbance may be an alteration in renal perfusion: reduced renal blood flow has consistently been demonstrated in these patients (Baldus et al, 1964b; Schroeder, Shear, Sancetta, and Gabuzda, 1967; Tristani and Cohn, 1967; Epstein, Berk, Hollenberg, Adams, Chalmers, Abrams, and Merrill, 1970) and this has been associated with an increased renal vascular resistance (Baldus, Summerskill, Hunt, and Maher, 1964c; Tristani and Cohn, 1967), a redistribution of blood flow away from the renal cortex (Baldus et al, 1964c; Shear, Kleinerman, and Gabuzda, 1965; Schroeder et al, 1967; Cohn, Tristani, and Khatri, 1970; Epstein et al, 1970; Kew, Brunt, Varma, Hourigan, Williams, and Sherlock, 1971), and a deterioration in renal function as assessed by the glomerular filtration rate (Baldus et al, 1964a; Shear et al, 1965). Thus far attempts to discover the cause of these circulatory changes have been directed towards finding some vasoactive substance

Received for publication 21 August 1972. released from or not metabolized by the cirrhotic liver or reflex renal vasoconstriction secondary to the disturbances in systemic haemodynamics which frequently occur in patients with cirrhosis of the liver (Epstein et al, 1970; Baldus, 1970; Barnardo, Summerskill, Strong, and Baldus, 1970). A recent report by Schroeder, Numann, and Chamberlain (1970) in which severe and prolonged oliguric renal failure in a patient with alcoholic cirrhosis was reversed by a portacaval anastomosis suggests that portal hypertension or the consequent portal circulatory changes may play a role in the pathogenesis of functional renal failure in cirrhosis. Although this is an isolated report, there is some experimental support for a relationship between the portal and renal circulations (Onnis, Schumacker, and Bounous, 1962). We have investigated this possibility by measuring renal and intrarenal blood flow and glomerular filtration rates in a group of patients with portal hypertension in the absence of cirrhosis.

\section{Materials and Methods}

Eleven patients with non-cirrhotic portal hypertension were studied. Of these, eight had portal vein thrombosis (associated with neonatal umbilical sepsis in two and of uncertain aetiology in the remainder) with normal hepatic histology and function; the other three (nos. 1, 2, and 7 in Table I) had congenital hepatic fibrosis but normal liver 
function. At the time they were studied, all patients had oesophageal varices and, with one exception, had bled from these. Apart from three patients (nos. 2, 6 , and 10) who had previously had a splenectomy, all had an enlarged spleen. Portal venography had been performed in every patient on one or other admission and the presence of collateral vessels confirmed. Splenic pulp pressures recorded at these times were invariably raised. As these pressures were recorded in only two patients during the same admission that renal perfusion was measured, no attempt was made to correlate intrasplenic pressures with renal blood flow. None of the subjects had ascites at the time they were investigated and urinary sodium excretion was normal. There were eight females and three males with a mean age of 24 years (range 12 to 49 years). None of the patients gave a history of renal disease and all had a normal blood urea and serum creatinine concentration, urine analysis, intravenous pyelogram, and renal arteriogram at the time they were investigated. In particular, the three patients with congenital hepatic fibrosis showed no evidence of the renal diseases which may be associated with this condition. All had a normal blood pressure and none showed evidence of cardiovascular disease.

Renal haemodynamic studies were carried out at the time of coeliac axis or superior mesenteric arteriography for the demonstration of the portal venous or hepatic arterial systems. Details of the procedure and its implications were explained to the patients and their consent was obtained. Renal and intrarenal blood flow was measured with the ${ }^{133}$ xenon washout technique. The details of our method were given in a previous paper (Kew et al, 1971). A dose of 600 to $1000 \mu \mathrm{Ci}$ of ${ }^{133}$ xenon dissolved in 0.8 to $1.0 \mathrm{ml}$ of sterile isotonic saline was used. An intraarterial injection of $250 \mu \mathrm{Ci}$ of ${ }^{133}$ xenon gives a maximal gonadal radiation dose of 1 millirad (Lassen, 1964). Background count rates were less than 30 counts per second while peak count rates after the injection were greater than 1500 counts per second. In most cases washout curves were recorded for only six minutes to allow repeated studies to be done. The curves were resolved into first (outer cortical blood flow) and second (juxtamedullary and outer medullary flow) components using an analog computer. Mean renal blood flow was calculated from the slope of the initial curve (Ingvar and Lassen, 1961). Flow rates were corrected for the patient's haematocrit as described by Andersen and Ladefoged (1967). The percentage distribution of blood flow to these regions of the kidney was calculated from the zero time intercept of each component (Dobson and Warner, 1957). Creatinine clearance was measured using the

\begin{tabular}{|c|c|c|c|c|c|c|}
\hline No. & Sex & Age & $\begin{array}{l}\text { Mean Renal Blood } \\
\text { Flow }(\mathrm{ml} / 100 \mathrm{~g} / \mathrm{min})\end{array}$ & $\begin{array}{l}\text { Outer Cortical } \\
\text { Rate }(\mathrm{m} / / 100 \mathrm{~g} / \mathrm{min})\end{array}$ & $\begin{array}{l}\text { Blood Flow } \\
\% \text { Distribution }\end{array}$ & $\begin{array}{l}\text { Creatinine Clearance } \\
\left(\mathrm{ml} / \mathrm{min} / 1 \cdot 73 \mathrm{~m}^{2}\right)\end{array}$ \\
\hline \multicolumn{7}{|c|}{ Controls } \\
\hline $\mathbf{A}$ & $\mathbf{F}$ & 22 & $\begin{array}{l}191 \\
191\end{array}$ & $\begin{array}{l}280 \\
322\end{array}$ & $\begin{array}{l}71 \\
61\end{array}$ & 106 \\
\hline B & $\mathbf{F}$ & 40 & $\begin{array}{l}286 \\
197\end{array}$ & $\begin{array}{l}325 \\
301\end{array}$ & $\begin{array}{l}78 \\
62\end{array}$ & 115 \\
\hline $\mathbf{c}$ & $\mathbf{M}$ & 23 & 261 & 359 & 81 & 116 \\
\hline \multicolumn{7}{|c|}{ Non-cirrhotic portal hypertension } \\
\hline 1 & $\mathbf{F}$ & 15 & $\begin{array}{l}271 \\
198\end{array}$ & $\begin{array}{l}343 \\
292\end{array}$ & $\begin{array}{l}78 \\
69\end{array}$ & 104 \\
\hline 2 & $\mathbf{F}$ & 27 & $\begin{array}{l}209 \\
291 \\
174 \\
125\end{array}$ & $\begin{array}{l}323 \\
392 \\
273 \\
348\end{array}$ & $\begin{array}{l}66 \\
68 \\
64 \\
50\end{array}$ & 99 \\
\hline 3 & $\mathbf{M}$ & 49 & $\begin{array}{l}78 \\
76\end{array}$ & $\begin{array}{l}169 \\
128\end{array}$ & $\begin{array}{l}34 \\
66\end{array}$ & 91 \\
\hline 4 & $\mathbf{F}$ & 29 & $\begin{array}{l}152 \\
129\end{array}$ & $\begin{array}{l}290 \\
277\end{array}$ & $\begin{array}{l}56 \\
48\end{array}$ & \\
\hline 5 & $\mathbf{M}$ & 13 & $\begin{array}{r}70 \\
141 \\
92\end{array}$ & $\begin{array}{l}151 \\
196 \\
170\end{array}$ & $\begin{array}{l}26 \\
69 \\
39\end{array}$ & 101 \\
\hline 6 & $\mathbf{F}$ & 30 & $\begin{array}{r}111 \\
111 \\
88\end{array}$ & $\begin{array}{r}150 \\
194 \\
88\end{array}$ & $\begin{array}{l}62 \\
51 \\
10\end{array}$ & 111 \\
\hline 7 & $\mathbf{F}$ & 21 & $\begin{array}{r}110 \\
62\end{array}$ & $\begin{array}{l}145 \\
204\end{array}$ & $\begin{array}{l}51 \\
25\end{array}$ & 47 \\
\hline 8 & $\mathbf{M}$ & 16 & $\begin{array}{l}54 \\
53 \\
92\end{array}$ & $\begin{array}{r}54 \\
53 \\
210\end{array}$ & $\begin{array}{l}10 \\
10 \\
41\end{array}$ & 75 \\
\hline 9 & $\mathbf{F}$ & 17 & 60 & 60 & 10 & 40 \\
\hline 10 & $\mathbf{F}$ & 12 & 55 & 164 & 29 & 48 \\
\hline 11 & $\mathbf{F}$ & 34 & 69 & 69 & 10 & 52 \\
\hline
\end{tabular}

Table I Mean renal and outer cortical blood flow and creatinine clearances in the 11 patients with non-cirrhotic portal hypertension and the control subjects 
standard method and corrected for body surface area.

Only three patients with a normal liver and kidneys and no portal hypertension were available as controls. The values for mean renal blood flow $(225 \pm 18 \mathrm{ml} / 100 \mathrm{~g} / \mathrm{min}$; mean $\pm \mathrm{SEM})$ and first component blood flow $\left(C_{1}\right)(317 \pm 11.8 \mathrm{ml} / 100 \mathrm{~g} /$ min) are lower than those found by Epstein et al (1970) using the same technique in 36 healthy individuals in whom renal arteriography was performed during assessment of their suitability as kidney donors $(338 \pm 7 \mathrm{ml} / 100 \mathrm{~g} / \mathrm{min}$ and $410 \pm$ $9 \mathrm{ml} / 100 \mathrm{~g} / \mathrm{min}$ respectively). The percentage distribution of blood flow to $C_{1}(71 \pm 3.6 \%)$ was similar to that found in the earlier study $(74 \pm 1 \%)$. Based on the findings in our three control subjects, we have taken the lower limits of normal for mean renal blood flow as $190 \mathrm{ml} / 100 \mathrm{~g} / \mathrm{min}, \mathrm{C}_{1} 300 \mathrm{ml} / 100 \mathrm{~g} / \mathrm{min}$, and percentage distribution to $C_{1}$ as 60 .

\section{Results}

Renal and outer cortical blood flow and creatinine clearances in the 11 patients with non-cirrhotic portal hypertension and the control subjects are shown in Table I. Renal perfusion was normal in two (nos. 1 and 2); in the remainder mean renal blood flow was reduced and there was a redistribution of intrarenal blood flow, the percentage of flow to the outer cortex being reduced while that to the juxtamedullary region and the outer medulla was increased. When the ${ }^{133}$ xenon washout curve was so slow that the first component could not be distinguished from

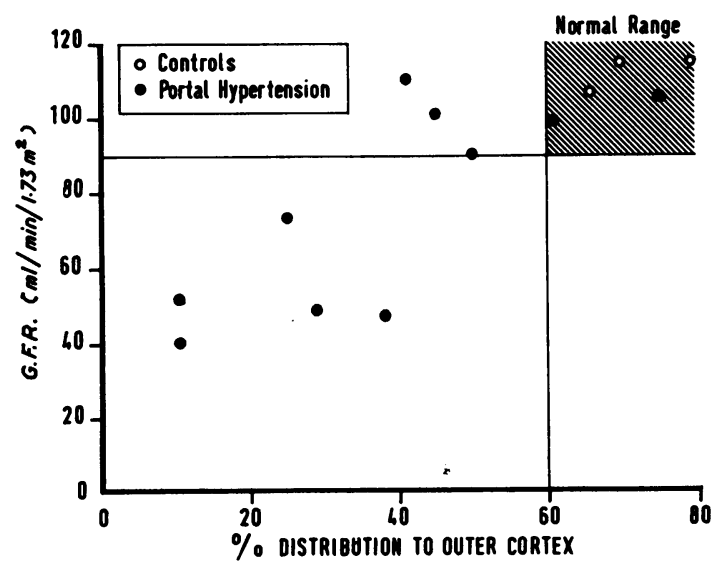

Fig. 1 Correlation between the percentage distribution of blood flow to the outer renal cortex and creatinine clearance in the patients with non-cirrhotic portal hypertension. the second, the percentage distribution of blood flow to the outer cortex was arbitrarily taken as $10 \%$. As these tracings appear to consist only of second and third components, the mean renal and juxtamedullary and outer medullary flow rates are the same if the former is calculated from the initial slope of the washout curve. In these circumstances the outer cortical flow rate was taken as being the same as the mean renal and second component flow rates. The percentage of renal blood flow distributed to the outer cortex ranged from 10 to 52 and there was a good correlation between this and the flow rate through the outer cortex $(r=0.77, P<0.001)$. There was also a good correlation between the percentage distribution of blood flow to the cortex and the creatinine clearance $(r=0.75, P<0.001)$ (Figure 1). When the outer cortex received more than $40 \%$ of the renal blood flow creatinine clearance was maintained but with lower figures the glomerular filtration rate fell. Variability between successive curves in individual patients was quite marked (Table I). Gross irregularity of the ${ }^{{ }^{133}}$ xenon washout was not encountered in the 26 tracings in the 11 patients. Four curves showed some irregularity although this was not sufficient to prevent accurate curve reading on the analog computer.

\section{Discussion}

The relationship if any between the portal and renal circulations in man has not been defined. There is some support for such a relationship in experimental animals. Tanche and Lemarchands (1958) found that occlusion of the portal vein was followed by a reduction in urine volume which occurred before the onset of systemic hypotension, and Onnis and his coworkers (1962) subsequently demonstrated that acute occlusion of the portal vein caused a marked fall in renal blood flow irrespective of any change in arterial blood pressure and dissociated from trapping of blood in the splanchnic bed. They suggested that renal vasoconstriction occurred as a consequence of interruption of normal portal venous drainage. A similar relationship has been demonstrated in dogs between the hepatic arterial and renal circulations and this has been shown to be mediated via the autonomic nervous system (Hori, Austen, and McDermott, 1965).

Alterations in renal haemodynamics frequently occur in patients with cirrhosis of the liver (Baldus et al, 1964b and 1964c; Shear et al, 1965; Schroeder et al, 1967; Tristani and Cohn, 1965; Epstein et al, 1970; Kew et al, 1971) and many of the subjects in whom this observation has been made have had portal hypertension. However, no attempt has hitherto been made to measure renal blood flow 
in patients with portal hypertension in the absence of cirrhosis or, apart from the report of Schroeder et al (1970), to incriminate portal hypertension or the resulting portal circulatory changes as a cause of the functional renal failure which may complicate advanced cirrhosis. We have found reduced renal blood flow in all but two of 11 patients with noncirrhotic portal hypertension and normal liver function. This was accompanied by a redistribution of intrarenal blood flow with a reduced flow through and percentage distribution to the outer cortex, while the percentage of blood flow to the juxtamedullary region and outer medulla was increased. Glomerular filtration is known to be decreased when the outer cortical glomeruli are bypassed (Trueta, Barclay, Daniel, Franklin, and Prichard, 1947; Hilton, Kanter, Hays, Bowen, Golub, Keating, and Wégria, 1955). In the present study there was a good correlation between outer cortical perfusion and the glomerular filtration rate: with normal or slightly reduced cortical blood flow creatinine clearance was maintained but in the five patients with poor renal and cortical perfusion the glomerular filtration rate fell. This pattern of disturbed renal circulation is similar to that reported in cirrhotic subjects with renal dysfunction or failure, and these findings raise the possibility that the renal haemodynamic changes in cirrhosis may be attributed at least in part to portal hypertension or portal circulatory changes. The observation that renal blood flow may be reduced in subjects with no obvious portal hypertension, together with the fact that functional renal failure has been reported as a complication of acute hepatitis (Summerskill, 1960) and hepatic tumours (Vesin, Roberti, and Viguié, 1965), indicates that more than one factor may be operative in altering renal perfusion. Furthermore, the fact that renal failure has not been reported to occur spontaneously in patients with extrahepatic portal hypertension suggests that the aetiological factors may be additive and that a further factor or factors is necessary before renal and cortical perfusion reaches that critical level at which azotaemia and oliguria supervene.

Variability and irregularity of the ${ }^{133}$ xenon washout similar to that seen in cirrhotic subjects (Epstein et al, 1970; Kew et al, 1971) was encountered in the patients with non-cirrhotic portal hypertension. This finding of marked haemodynamic instability has been put forward as evidence that the renal ischaemia in cirrhotic patients with functional renal failure is due to active vasoconstriction (Epstein et al, 1970). The mechanisms controlling renal vascular resistance and intrarenal blood flow are complex. The rich adrenergic and cholinergic innervation of the renal vessels and their responsiveness to neurogenic stimulation suggests that the autonomic nervous system may play an important role in regulating renal and intrarenal blood flow (Barger and Herd, 1971). In this regard it has been shown (Barger and Herd, 1971) that the outer cortical vessels are particularly sensitive to sympathetic vasoconstrictor stimuli and an increase in sympathetic tone might therefore be expected to affect mainly cortical blood flow. The pathogenesis of renal vasoconstriction in portal hypertension is not known but several possible mechanisms have been considered. Although the circulating blood volume is normal or increased in patients with cirrhosis (McCloy, Baldus, Tauxe, and Summerskill, 1967; Lieberman and Reynolds, 1967), it has been argued that the 'effective' plasma volume is reduced in the presence of portal hypertension because of the sequestration of blood in the hypertensive splanchnic bed (Vlahcevic, Adham, Jick, Moore, and Chalmers, 1965), and that this may reflexly be responsible for the reduced renal perfusion. Most short-term attempts at improving renal blood flow by expanding plasma volume have not been successful (Tristani and Cohn, 1967; McCloy, Baldus, Maher, and Summerskill, 1967; Reynolds, Lieberman, and Redeker, 1967) but Schroeder et al (1970) believe that a more permanent increase in 'effective' plasma volume may be produced by decompression of the portal system and that this may have been responsible for the improvement in renal perfusion and function which occurred in their patient. Alternatively, the changes may be mediated directly from the portal to the renal circulations via the autonomic nervous system. The experimental work of Onnis et al (1962) and Hori et al (1966) favour this mechanism. A further possibility is that some vasoactive substance produced in the bowel and normally catabolized in the liver gains access to the systemic circulation by way of porta-systemic collateral vessels and exerts an effect directly on the renal vessels.

These observations are at the moment of theoretical rather than practical importance because patients with advanced cirrhosis of the liver who develop functional renal failure and might possibly benefit, as did the patient of Schroeder and his coworkers, from a portal decompression operation, are rarely fit enough to undergo major surgery. Nevertheless they may contribute to our understanding of the interrelationships between the liver and kidney and the pathogenesis of functional renal failure in cirrhosis.

M.C.K. is in receipt of a grant from the Wellcome Foundation and R.R.V. a grant from the Medical College of Wisconsin. Financial support for the study was provided by the Ingram Trust. We are grateful to $\mathrm{Mr} \mathrm{D}$. Sampson and our colleagues in the Department of Radiology for their assistance. 


\section{References}

Andersen, A. M., and Ladefoged, J. (1967). Partition coefficient of ${ }^{138}$ xenon between various tissues and blood in vivo. Scand. $J$. clin. lab. Invest., 19, $72-78$.

Baldus, W. P. (1970). Etiology and management of renal failure in cirrhosis and portal hypertension. Ann. N.Y. Acad. Sci., 170, 267-276.

Baldus, W. P., Feichter, R. N., and Summerskill, W. H. J. (1964a). The kidney in cirrhosis. I. Clinical and biochemical features of azotemia in hepatic failure. Ann. intern. Med., 60, 353-365.

Baldus, W. P., Feichter, R. N., Summerskill, W. H. J., Hunt, J. C., and Wakim, K. G. (1964b). The kidney in cirrhosis. II. Disorders of renal function. Ann. intern. Med., 60, 366-377.

Baldus, W. P., Summerskill, W. H. J., Hunt, J. C., and Maher, F. T. (1964c). Renal circulation in cirrhosis: observations based on catheterisation of the renal vein. J. clin. Invest. 43, 1090-1097.

Barger, A. C., and Herd, J. A. (1971). The renal circulation. New Engl. J. Med., 284, 482-490.

Barnardo, D. E., Summerskill, W. H. J., Strong, C. G., and Baldus, W. P. (1970). Renal function, renin activity and endogenous vasoactive substances in cirrhosis. Amer. J. dig. Dis., 15, 419425.

Cohn, J. N., Tristani, F. E., and Khatri, I. M. (1970). Renal vasodilator therapy in the hepatorenal syndrome. Med. Ann. D. C., 39, 1-7.

Dobson, E. L., and Warner, G. F. (1957). Measurement of regional sodium turnover rates and their application to the estimation of regional blood flow. Amer. J. Physiol., 189, 269-276.

Epstein, M., Berk, D. P., Hollenberg, N. K., Adams, D. F., Chalmers, T. C., Abrams, H. L., and Merrill, J. P. (1970). Renal failure in the patient with cirrhosis. The role of active vasoconstriction. Amer. J. Med., 49, 175-185.

Hilton, J. G., Kanter, D. M., Hays, D. R., Bowen, E. H., Golub, J. R., Keating, J. H., and Wégria, R. (1955). The effect of acute arteriovenous fistula on renal functions. J. clin. Invest., 34, 732-736.

Hori, M., Austen, W. G., and McDermott, W. V., Jr. (1965). Role of hepatic arterial blood flow and hepatic nerves on renal circulation and function. I. Acute studies in the dog. Ann. Surg., $162,849-862$

Ingvar, D. H., and Lassen, N. A. (1961). Quantitative determination of regional cerebral blood flow in man. (A preliminary communication.) Lancet, 2, 806-807.

Kew, M. C., Brunt, P. W., Varma, R. R., Hourigan, K. J., Williams, H. S., and Sherlock, S. (1971). Renal and intrarenal blood-flow in cirrhosis of the liver. Lancet, 2, 504-510.

Koppel, M. H., Coburn, J. W., Mims, M. M., Goldstein, H., Boyle, J. D., and Rubini, M. E. (1969). The transplantation of cadaveric kidneys from patients with hepato-renal syndrome.
Evidence for the functional nature of renal failure in advanced liver disease. New Engl. J. Med., 280, 1367-1371.

Lassen, N. A. (1964). In Radioaktive Isotope in Klinik und Forschung (International Symposium at Bad Gasein), p. 37.

Lieberman, F. L., and Reynolds, T. B. (1967). Plasma volume in cirrhosis of the liver: its relation to portal hypertension, ascites and renal failure. J. clin. Invest., 46, 1297-1308.

McCloy, R. M., Baldus, W. P., Maher, F. T., and Summerskill, W. H. J. (1967). Effects of changing plasma volume, serum albumin concentration, and plasma osmolality on renal function in cirrhosis. Gastroenterology, 53, 229-239.

McCloy, R. M., Baldus, W. P., Tauxe, W. N., and Summerskill, W. H. J. (1967). Plasma volume and renal circulatory function in cirrhosis. Ann. intern. Med., 66, 307-311.

Onnis, M., Schumacker, H. B., Jr., and Bounous, G. (1962). Response to occlusion of the portal vein: blood pressure and renal blood flow. Arch. Surg., 85, 897-900.

Papper, S., Belsky, J. L., and Bleifer, K. H. (1959). Renal failure in Laennec's cirrhosis of the liver. I. Description of clinical and laboratory features. Ann. intern. Med., 51, 759-773.

Reynolds, T. B., Lieberman, F. L., and Redeker, A. G. (1967) Functional renal failure with cirrhosis. The effect of plasma expansion therapy. Medicine (Baltimore), 46, 191-196.

Schroeder, E. T. Numann, P. J., and Chamberlain, B. E. (1970) Functional renal failure in cirrhosis. Recovery after portacaval shunt. Ann. intern. Med., 72, 923-928.

Schroeder, E. T., Shear, L., Sancetta, S. M., and Gabuzda, G. J. (1967). Renal failure in patients with cirrhosis of the liver. III. Evalua tion of intrarenal blood flow by para-aminohippurate extraction and response to angiotensin. Amer. J. Med., 43, 887-896.

Shear, L., Kleinerman, J., and Gabuzda, G. J. (1965). Renal failure in patients with cirrhosis of the liver. I. Clinical and pathologic characteristics. Amer. J. Med., 39, 184-198.

Summerskill, W. H. J. (1960). Pathogenesis and treatment of disorders of water and electrolyte metabolism in hepatic disease. Proc. Mayo Clin., 35, 89-97.

Tanche, M., and Lemarchands, H. (1958). Un mécanisme possible de l'arrêt de la diurèse consecutif à l'interruption de la circulation porte. J. Physiol. (Paris), 50, 538-540.

Tristani, F. E., and Cohn, J. N. (1967). Systemic and renal hemodynamics in oliguric hepatic failure: effect of volume expansion J. clin. Invest., 46, 1894-1906.

Trueta, J., Barclay, A. E., Daniel, P. M., Franklin, K. J., and Prichard, M. M. L. (1947). Studies of the Renal Circulation, p. 126-156. Thomas, Springfield, Illinois. Blackwell, Oxford.

Vesin, P., Roberti, A., and Viguié, R. (1965). Défaillance rénale fonctionnelle terminale chez des malades atteints de cancer du foie, primitif ou sécondaire. Sem. Hóp. Paris, 41, 1216-1220.

Vlahcevic, Z. R., Adham, N. F., Jick, H., Moore, E. W., and Chalmers, T. C. (1965). Renal effects of acute expansion of plasma volume in cirrhosis. New Engl. J. Med., 272, 387-391. 